\title{
Correction: Parp mutations protect from mitochondrial toxicity in Alzheimer's disease
}

Yizhou Yu, Giorgio Fedele (D), Ivana Celardo, Samantha H. Y. Loh and L. Miguel Martins (D)

(c) The Author(s) 2021

Cell Death and Disease (2021)12:720; https://doi.org/10.1038/s41419-021-03976-2

Correction to: Cell Death and Disease

https://doi.org/10.1038/s41419-021-03926-y,

published online 25 June 2021

The original version of this article unfortunately contained several mistakes in figures:

For Figures $1 \mathrm{~A}$ and $1 \mathrm{C}$, the text and number in oblongs should be highlighted in red and blue, not red and grey. For Figure $2 \mathrm{C}$, the imaged area should be fully coloured in pink. For Figures 5 and 6 please see the correct figures below. We sincerely apologize for these typeset error. The corrected figures can be found below. The original article has been corrected.

Fig. 1.

A

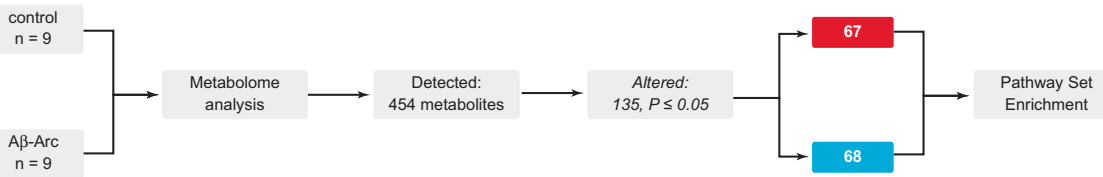

B

Fold-enrichment (A $\beta$-Arc versus control)

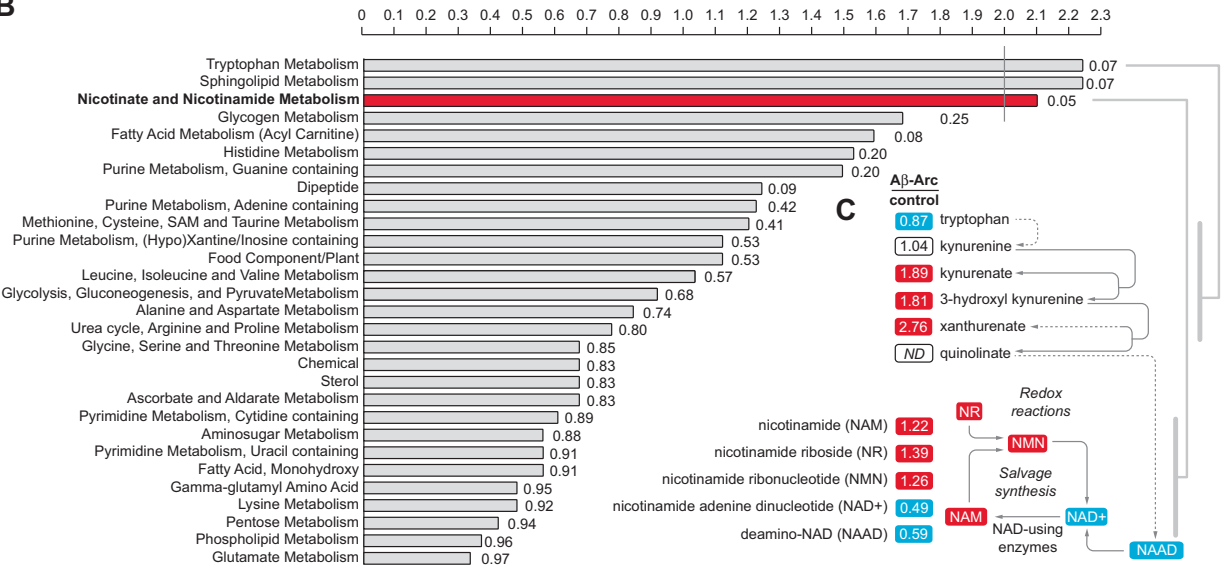


Fig. 2.

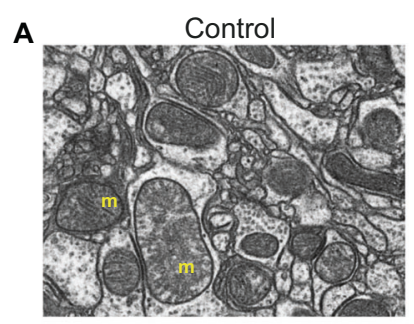

A

C

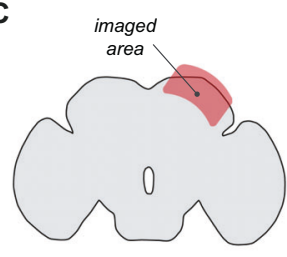

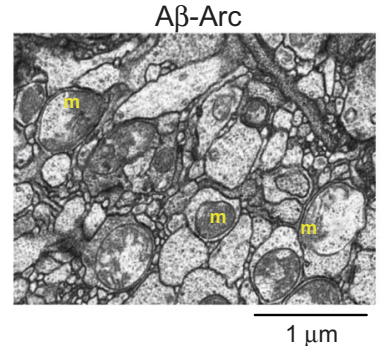

Control

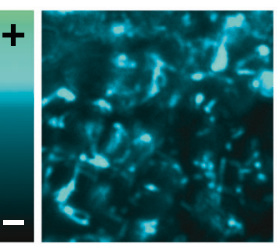

$A \beta-A r c$

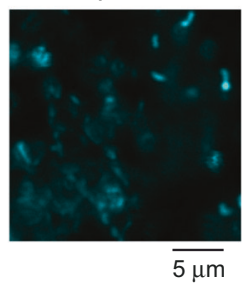

B

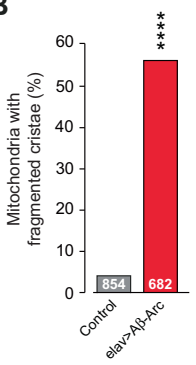

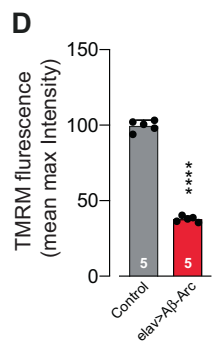

Fig. 5.

A

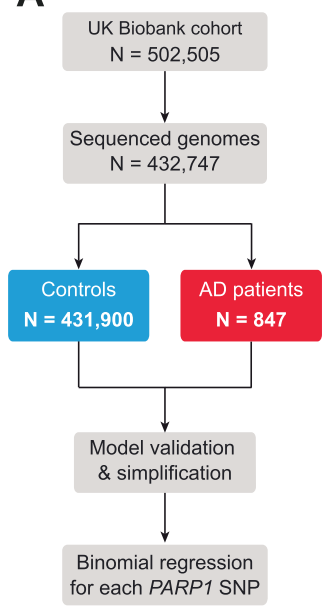

B

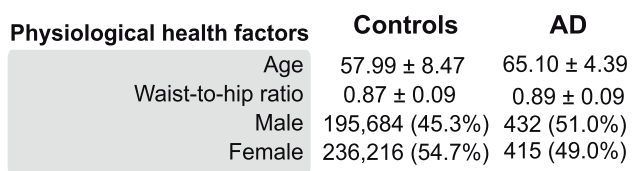

Social health determinants

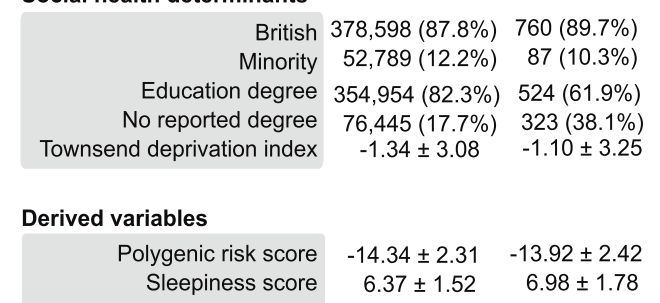

C

\begin{tabular}{|c|c|c|c|c|}
\hline rsid & bp & ref_seq & minor & maf \\
\hline rs1136410 & 226367601 & A & G & 0.1608 \\
\hline rs114939615 & 226403886 & G & A & 0.0449 \\
\hline rs142376976 & 226390577 & C & A & 0.0005 \\
\hline rs149632681 & 226402077 & C & T & 0.0014 \\
\hline rs1805407 & 226402132 & T & C & 0.2334 \\
\hline rs1805410 & 226380964 & T & C & 0.1315 \\
\hline rs2230484 & 226383066 & G & A & 0.0030 \\
\hline rs3219062 & 226383047 & G & T & 0.0015 \\
\hline rs3219090 & 226376990 & T & C & 0.5725 \\
\hline rs3219123 & 226367647 & G & A & 0.0398 \\
\hline rs3219134 & 226366564 & T & C & 0.0152 \\
\hline rs3219139 & 226365482 & A & C & 0.0248 \\
\hline rs3219145 & 226363128 & T & C & 0.0025 \\
\hline rs78797064 & 226373275 & T & G & 0.0122 \\
\hline rs8679 & 226360853 & A & G & 0.1525 \\
\hline
\end{tabular}

D

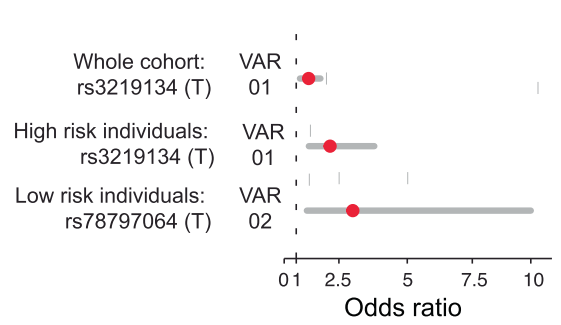

F

Positive AD diagnosis

Sex (male relative to female)

$$
\text { Age }
$$

Townsend deprivation index

$\begin{array}{lrl}0.2 & 0.4 & 0.6 \\ \beta \text { values } & \end{array}$

\section{$\begin{array}{llll}\text { E } & \text { rs3219134 } & \text { [s78797064 } & \text { rs2230484 }\end{array}$}

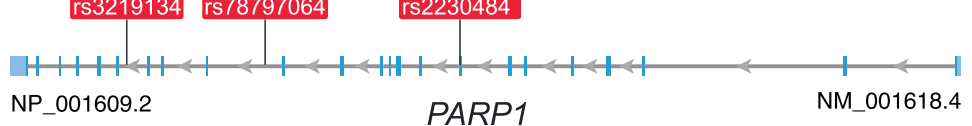

H

\section{G}

Confounder variab

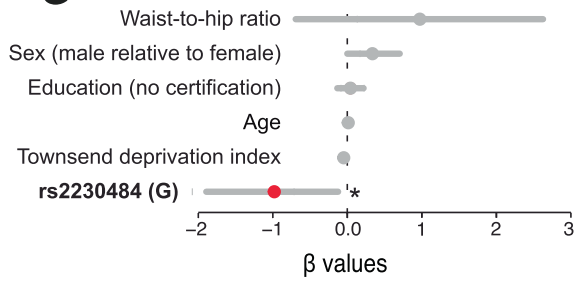

\begin{tabular}{|c|c|}
\hline rs3219134 & Sequence \\
\hline ESE_Tra2 (ESE Site Broken) & AAAAC \\
\hline RESCUE ESE (New ESE Site) & G AAACA \\
\hline RESCUE ESE (New ESE Site) & TG AAAC \\
\hline EIE (New ESE Site) & TG AAAC \\
\hline RESCUE ESE (New ESE Site) & ATG AAA \\
\hline EIE (New ESE Site) & ATG AAA \\
\hline ESE_Tra2 (ESE Site Broken) & AATAA \\
\hline ESE_9G8 (New ESE Site) & AATG AA \\
\hline RESCUE ESE (New ESE Site) & AATG AA \\
\hline EIE (New ESE Site) & AATG AA \\
\hline EIE (New ESE Site) & AAATG A \\
\hline PESS (ESS Site Broken) & AAATAAAA \\
\hline PESS (ESS Site Broken) & AAAATAAA \\
\hline
\end{tabular}


Fig. 6.

A

Whole cohort
Subset with high genetic risk for $A D$

B

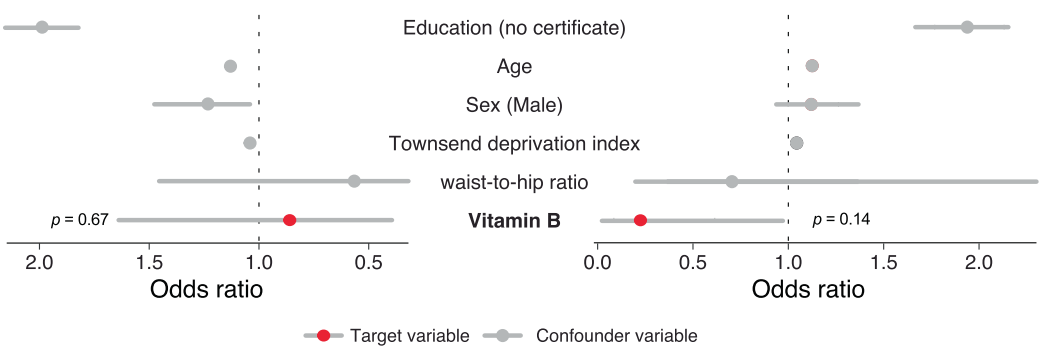

C

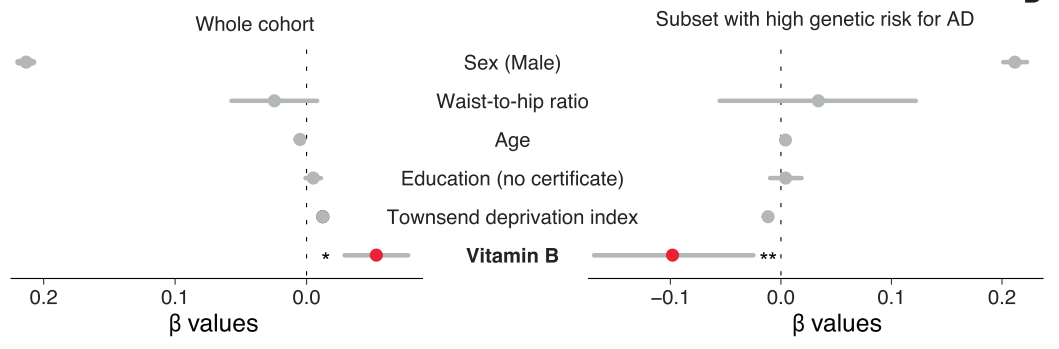

(c) Open Access This article is licensed under a Creative Commons Attribution 4.0 International License, which permits use, sharing, adaptation, distribution and reproduction in any medium or format, as long as you give appropriate credit to the original author(s) and the source, provide a link to the Creative Commons license, and indicate if changes were made. The images or other third party material in this article are included in the article's Creative Commons license, unless indicated otherwise in a credit line to the material. If material is not included in the article's Creative Commons license and your intended use is not permitted by statutory regulation or exceeds the permitted use, you will need to obtain permission directly from the copyright holder. To view a copy of this license, visit http://creativecommons. org/licenses/by/4.0/.

(c) The Author(s) 2021 